
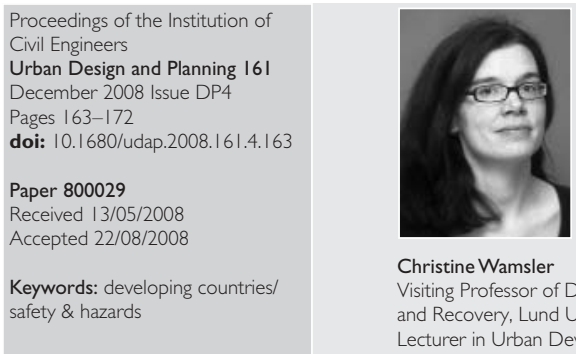

Christine Wamsler

Christine Wamsler
Visiting Professor of Disaster Management

and Recovery, Lund University, Sweden

Lecturer in Urban Development, University

of Manchester, UK

\title{
Achieving urban resilience: understanding and tackling disasters from a local perspective
}

\section{C.Wamsler PhD, MA, Dipl. Ing.}

The damage caused by a dramatic worldwide increase in so-called natural disasters is staggering, with the poor in developing countries being most at risk. This paper analyses: (a) the key variables and their causal relations that underlie the complex system of risk and disaster occurrence in slums; (b) the impacts of disasters on slums; (c) the strategies used by local people to cope with risk and disasters; and (d) the reasons for weak coping. The views and knowledge of slum dwellers in EI Salvador are the focus of this analysis. On this basis, five complementary ex ante risk-reduction measures have been identified and developed to match local needs, capacities and dimensions of risk—hazard reduction (or prevention), mitigation, preparedness, risk 'financing' and stand-by for recovery. The complementary measures provide a frame of reference that allows urban development actors to systematically search for and design potential risk reduction measures. It is concluded that keeping these measures compartmentalised and separate from each other during planning and implementation of urban development programmes helps ensure both sustainable poverty reduction and urban resilience.

\section{INTRODUCTION}

Over recent decades, the frequency of 'natural' disasters has grown significantly worldwide. In fact, the number of such disasters has quadrupled over the last 30 years, resulting in escalating human and economic losses. ${ }^{1}$ In 2005 alone, over 360 disasters were reported in which around 92000 people were killed, another 160 million suffered adverse impacts and direct material losses of about US\$ 160 billion were incurred. Developing countries bear the highest losses in terms of human lives and gross domestic product, and El Salvador is no exception to this. On the contrary, being located in one of the most disaster-prone regions in the world, the country is strongly affected by natural disasters. ${ }^{2}$

The urban poor who live in so-called slums are particularly vulnerable to 'natural' disasters such as earthquakes, floods, landslides, windstorms, volcanic eruptions, wild fires, water surges and droughts. Their settlements, often located on marginal land near rivers or on steep slopes, comprise substandard housing and infrastructure. Among other risk factors are leaking sewage pipes from better-off settlements that pass through slum areas, lack of water and waste management services, scarce resources, limited access to disaster-related information and insurance mechanisms, and overcrowding. While poverty reinforces slum dwellers' vulnerability to natural hazards, disasters make their already precarious living conditions worse, creating a vicious circle of poverty. Currently, more than one billion people worldwide live in slums. ${ }^{3}$ It is estimated that this number will double over the next 25 years, increasing the number of people forced to accept living conditions that are dangerous and beneath human dignity. The threat of climate change presents an even more worrying outlook in this context. ${ }^{4,5}$

In recent years, increasing attention has been paid to the need to reduce disaster risk, not only within the post-disaster phase, but also-and especially-within the context of development work. Risk is defined here as the probability of harmful consequences or losses (e.g. deaths, injuries, property damages, social and economic disruption, environmental degradation) resulting from interactions between natural and humaninduced hazards $(H)$, vulnerable conditions $(V)$ and the lack of capacity of households, communities and/or institutions to respond to and recover from disasters. Risk reduction has become a popular term used to bring together measures to minimise disaster risk throughout a society, to avoid or limit the adverse impacts of hazards within the broad context of sustainable development. It is also a component of successful reconstruction. ${ }^{6}$

One of the stated aims of the UN millennium declaration, ${ }^{7}$ that is to achieve a significant improvement in the lives of at least 100 million slum dwellers by 2020, alludes to the need to reduce disaster risk and the Hyogo framework for action 2005$2015^{8}$ urges governments to address the issue of disaster risk in their sector development planning and programmes. However, aid organisations working in urban development, including assistance for social housing and human settlement planning, still struggle to sustainably reduce existing disaster risk in the course of their everyday work.

\section{A better understanding of}

(a) the underlying drivers of risk and disaster occurrence in slums and

(b) the household coping strategies employed to deal with risk and disaster impacts 
is an urgent first step towards achieving sustainable urban resilience. In this context, resilience is understood as the capacity of a community, society or system to withstand or resist hazards and/or disasters; that is, to maintain an acceptable functional and structural standard by (a) adapting and (b) 'bouncing back' rapidly so as to deal adequately with current and future threats. More precisely, the idea of resilience reflects a functioning disaster-risk-reduction system that works before, during and after disasters, suggesting, in essence, a proactive stance towards risk. It has its origin partly within ecological theory and partly in systems analysis and disaster studies.

\section{OBJECTIVES AND METHODOLOGY}

This paper is based on case studies (conducted within the framework of a broader research study ${ }^{9-11}$ ) carried out at household level in El Salvador during 2005 and 2006 and follow-up desk research during 2007. The objective is to investigate-from a local perspective-existing disaster risk, its related causes and impacts, and the local strategies used to cope with risk and disasters, including how these efforts could be (better) supported by urban development actors. (Note that the term 'urban development actor' here is used as an umbrella term for stakeholders/organisations that work in the field of urban development, including social housing and human settlement planning. This includes international, national, municipal and local governmental and non-governmental organisations (NGOs) that are directly engaged at local household level and/ or support related activities.) In short the main focus is thus on analysing the key variables-and their causal relations-that underlie the complex system of risk and disaster occurrence in slum areas, together with how this system can be positively influenced.

The outcomes provide an understanding of what households perceive, experience, undertake and, indeed, need in order to cope with disaster risk and disaster impacts. On this basis, the type of assistance provided by urban development actors was analysed to yield important insights into how assistance for urban development could be improved.

The research at local household level included observation, walk-through analyses and interviews with 62 households (a total of 331 persons) in disaster-prone slums. The sample of interviewees selected was large in relation to the defined target population. This target population, consisting of 100 households, was purposely selected and defined as households located within the extreme high-risk areas of 15 slum communities. Those households most at risk were defined as those that were most affected during winter 2005 (a season characterised by a tragic combination of Hurricane Stan, floods, landslides, small-scale earthquakes and the eruption of the Ilamatepec volcano). The 100 households were identified by censuses conducted locally and/or post-disaster evaluations carried out by aid organisations working within these communities. To obtain significant, credible and representative responses, 62 of the 100 households were interviewed, providing, at a confidence level of 95\%, a maximum margin of error of around $8 \%$. The selection of these 62 households, and also of the representative(s) of each household interviewed, was based on a combination of stratified and random sampling: with the help of aid organisations and local key informants, the most information-rich households and household members were identified within the different high-risk areas in the 15 slum communities, trying not to leave out any subgroups. This procedure was followed by random sampling within each group to make a final sample selection. This sampling procedure was carried out with the help of, among other things, maps of each programme area and the numeration of the respective households (which allowed random selection of local households on a numerical basis). In practice, the sampling procedure described was time-consuming and difficult to follow rigorously all the time. Thus, some improvisation and flexibility were necessary. For instance, in the end many interviews were held with more than one household member, who assisted from the beginning or was called when needed to provide, for instance, additional information as regards expenses, income and/or specific coping strategies used. In order to deal with bias in the selection of households and interviewees, different types of triangulation were used.

In-depth evaluations of four urban development projects implemented in these slum areas were also carried out. A combination of grounded theory ${ }^{12}$ and systems analysis ${ }^{13}$ was applied for data analysis.

In the following, analyses of the current situation in El Salvador will be presented, providing a 'snapshot' from the household level of the selected slum communities. Discussed are the significance of disaster occurrence, its underlying drivers and impacts on slum dwellers, household strategies to cope with risk and disasters, the financial implications of these strategies for slum dwellers, and the reasons for weak coping. Slum dwellers' views and their extensive knowledge as to what makes them vulnerable or resilient to natural disasters are the focus of the discussion. Conclusions are drawn regarding the needs of slum dwellers and the risk reduction measures that could assist in improving development actors' assistance to effectively and sustainably achieve urban resilience.

\section{UNDERSTANDING RISK AND DISASTER OCCURRENCE IN SLUMS}

Flooding and landslides affect many slum dwellers in the areas analysed-not just sporadically but annually, usually during the winter period. The likely occurrence of these hazards/disasters was generally considered by slum dwellers to be the main risk to their lives and livelihoods. Earthquakes and windstorms were next in importance. Lack of job opportunities, inadequate water provision and the insecurity caused by violent juvenile gangs (maras) were also seen as substantial 'risks'. The word 'risk' is in quotation marks as, in this paper, the term generally refers to risk associated with natural disasters and/or hazards, and not to socio-economic hazards. However, as slum dwellers mentioned such hazards as part of the risk they face, some of the main related aspects are mentioned here. Note, however, that-in keeping with the focus of this study-these were of secondary importance to slum dwellers compared with the risk caused by natural hazards.

Causal loop diagrams, one of the main tools of systems analysis, were used to develop illustrative models of the key variables and the causal relations influencing risk and disaster occurrence in the slums analysed. (The computer programme Vensim ( ${ }^{14}$ was used to support creation of the diagrams/ models, which can be used as a basis for computer simulations.) 


\section{$A \longrightarrow B \quad$ Increase in $A$ effects increase in $B$ \\ $A \longrightarrow B \quad$ Increase in $A$ effects decrease in $B$}

Fig. I. Illustration of positive and negative causal relations between two variables

A causal relation between two variables is portrayed by an arrow with a plus (+) or minus (-) sign. As shown in Fig. 1, the sign indicates the type of change that occurs if variable $A$ increases. A positive symbol means that an increase in $A$ effects an increase in $B$; a negative symbol indicates that an increase in $A$ results in a decrease in $B$.

The inclusion of non-linear relationships is one of the most important advantages of causal loop diagrams over conventional models such as flow charts. Causal loop diagrams usually have at least one closed loop, representing feedback. Reinforcing feedback loops are circular relations between various variables, all of which are connected with arrows going in the same direction (see Fig. 2). These reinforcing feedback loops are generally highlighted with bold arrows and indicate situations where vicious circles may arise.

\section{I. Natural drivers}

When slum dwellers were asked about the underlying drivers of risk and disaster occurrence, most referred primarily to natural drivers (i.e. weather (rain) and soil conditions). Fig. 3 illustrates how the identified key variables 'rain' and 'unstable soil

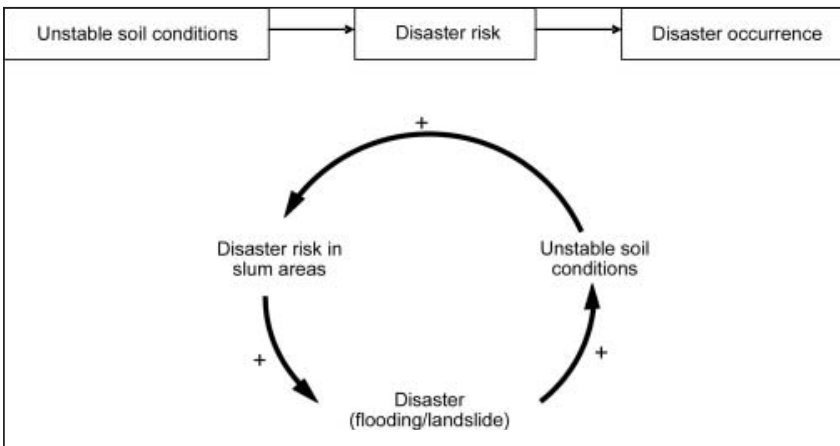

Fig. 2. Flow diagram and corresponding causal loop diagram

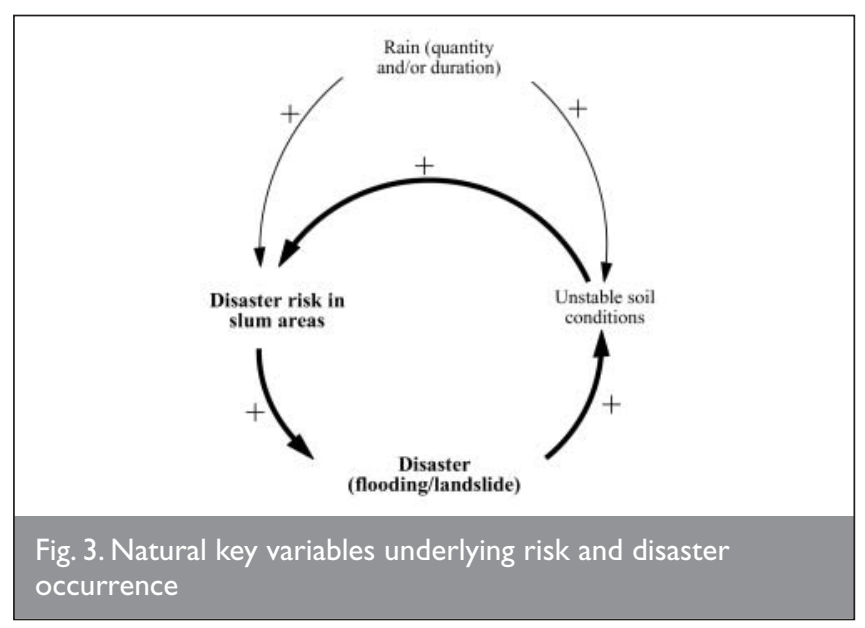

conditions' relate to risk and disaster occurrence. As can be seen, an increase in the amount or duration of rain could increase disaster risk and hence the occurrence of flooding and landslides. (Note that the relation between disaster risk and disaster occurrence is definitional. However, it is important to illustrate the variables separately in order to show causal loops as affected by disaster occurrence, i.e. not by disaster risk.) In turn, flooding and landslides can make unstable soil conditions worse, resulting in a further exacerbation of disaster risk. In addition, more rainfall destabilises unstable soil conditions, which again influences the occurrence of risk and disaster.

Upon probing, the majority of interviewees were aware of other factors that increase their vulnerability. In fact, apart from natural drivers, it was possible to identify space-related, infrastructure-related, socio-economic, organisational and institutional drivers, which are presented in figures 4-7. A range of variables are inherent to different sub-diagrams and interconnect the different thematic loops. Those interconnecting variables are only partially included in the figures presented here. In all the thematic causal loop diagrams presented, some influencing variables from other thematic groups are also included. For instance, in Fig. 4, 'number of households/household sizes' is a socio-economic factor. However, it was included in the diagram as it has an important influence on space-related aspects.

\subsection{Space-related drivers}

Interviewees reported on residents' different strategies to gain living space or to expand it to cope not only with the growing number and size of slum households but also with the lack of alternative living areas. Among the strategies reported by the interviewees were, for instance, residents living downhill felling trees or excavating the slopes below their houses; residents uphill building latrines close to a declivity; and other residents claiming land from nearby rivers. As illustrated in Fig. 4, a vicious circle can develop, with the increasing need for living space forcing people to expand their living areas. Under slum conditions, this often results in unsuitable buildings and

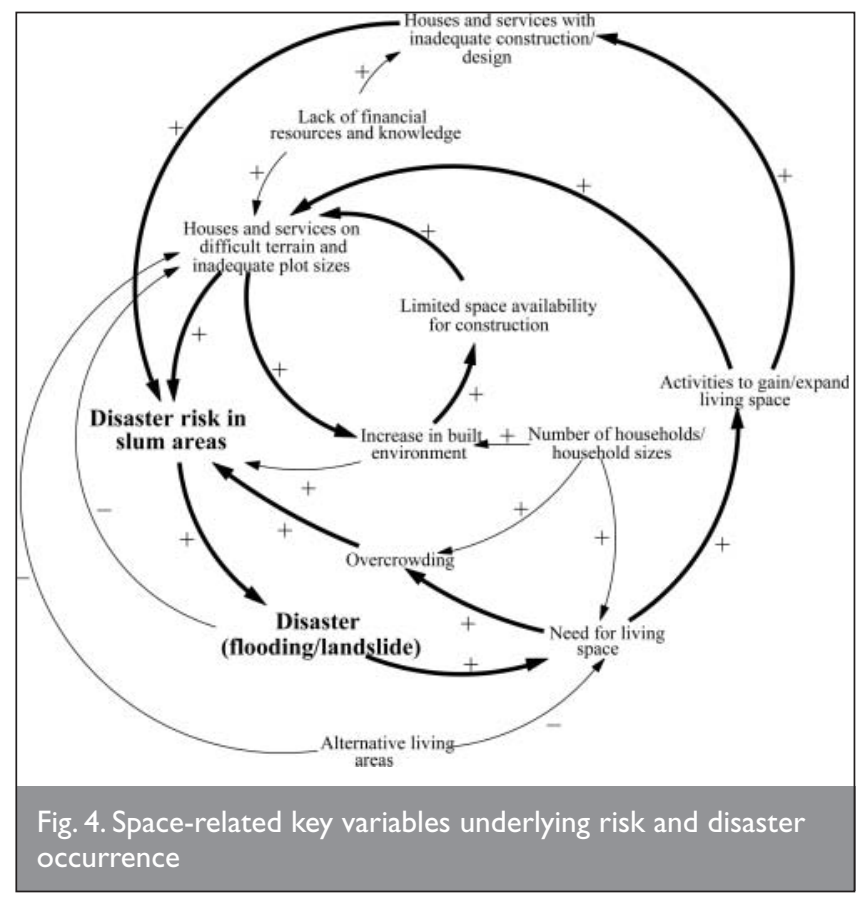


services being constructed in inadequate locations and on under-sized plots (Fig. 4). This is related to a lack of financial resources, knowledge and available space for mitigation works. The outcome can be increased disaster risk and hence floods and landslides; loss of housing and land under these conditions increases the need for living space still further. Moreover, an increasing built environment, in terms of space, density and overcrowding, fosters disaster risk. Fig. 4 portrays the related key variables.

\subsection{Infrastructure-related drivers}

Lack of adequate infrastructure (e.g. for waste collection, pedestrian and vehicle circulation, and rain and waste water) was another key variable identified (Fig. 5). Slum dwellers reported that uphill neighbours were allowing waste and storm water to flow on to their land and people from both inside and outside the settlement were tipping solid waste down hills or into nearby rivers. Insufficient knowledge about how to reduce existing risk and the conventional belief that disasters are purely 'divinely driven' may-together with a range of other factors-foster such behaviour. The outcome is blockage of water gutters and river flows, and unstable constructions, such as pathways and housing. Fig. 5 illustrates related key variables and causal relations.

\subsection{Socio-economic (and organisational) drivers}

The lack of financial resources due, among other things, to unemployment and low income, was mentioned frequently as one of the underlying causes of risk and disasters (Fig. 6). The research indicated that lack of financial resources, as well as the obvious influence that this has on the quality of housing and infrastructure and on people's ability to absorb disaster impacts, further influences individuals' community engagement (Fig. 6). In fact, as people need to take several jobs and also take care of family members, they have little time left for community efforts to reduce risk. Furthermore, better-off household members opt out of community involvement, which can have a negative effect not only on social cohesion but on the disaster resilience of the entire community. A general mistrust of community cohesion and the local community organisation was also identified. This was related, among other things, to corruption, co-optation and political factionalism (Fig. 6).

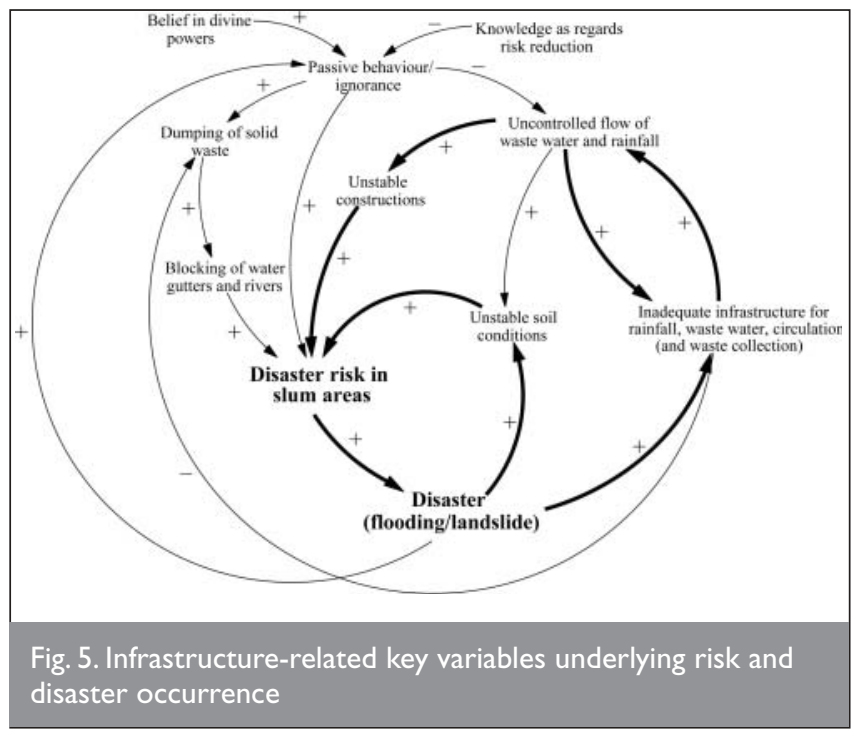

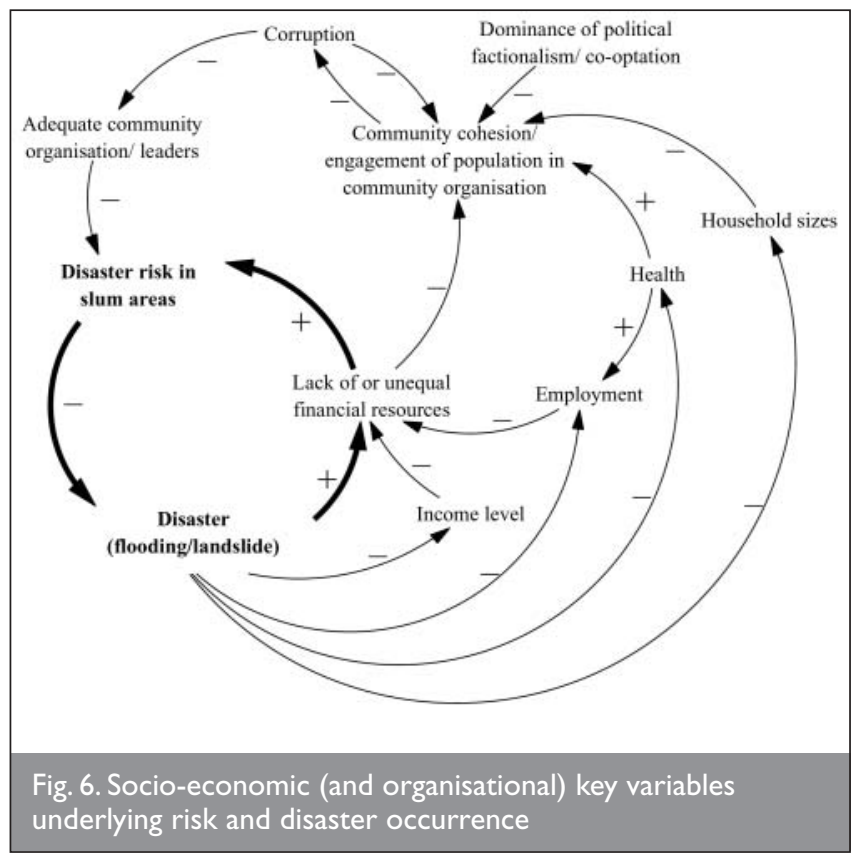

Figure 6 further highlights a vicious circle that could develop. Disaster affects people's already poor financial situation by, for instance, reducing their income and incurring additional expense for reconstruction. Hence, increased disaster occurrence can result in an increased lack of financial resources and an increase in differences in financial levels. This, in turn, increases people's disaster risk.

\subsection{Institutional drivers}

Lack of, or inadequate, outside assistance was further mentioned by slum dwellers as an important aspect making them particularly vulnerable in terms of facing increasing risk and disasters. In fact, national and municipal governments were often seen as unhelpful, even a hindrance, to slum dwellers' efforts to improve their situation. The actions taken by planning authorities and information obtained by them with respect to the development and legalisation of planned settlements were often seen as contradictory and unreliable. However, adequate outside help was seen as crucial for, among other things, easing people away from passive behaviour (Fig. 7).

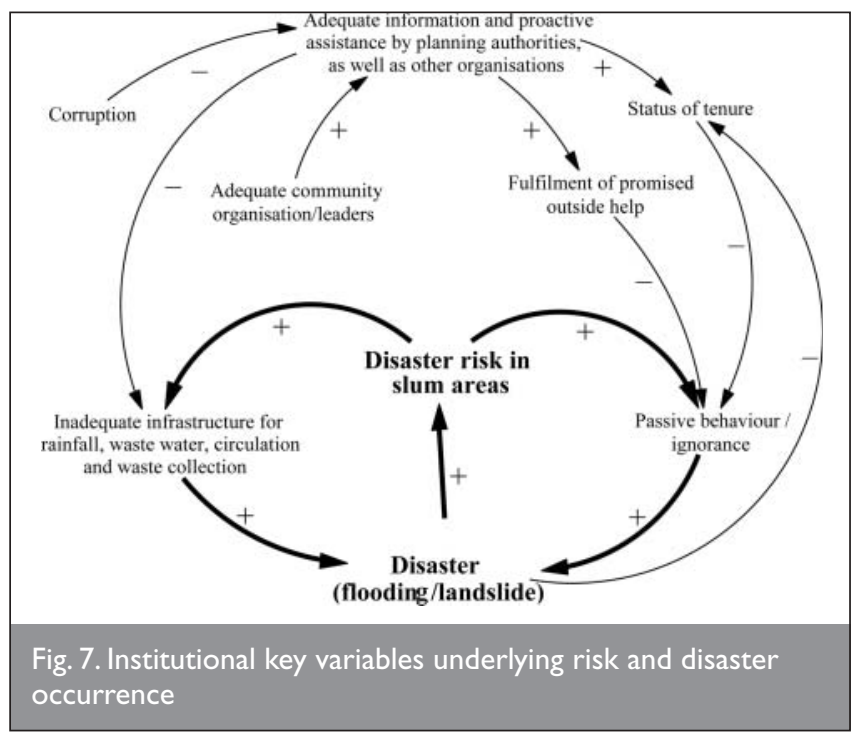


The incremental improvement of housing and infrastructure in slums, which reduces disaster risk, is generally supported by governmental and non-governmental organisations (NGOs), religious institutions and political parties. Unequal distribution of support of this kind was identified as being related to the level of community organisation, levels of corruption and slum dwellers' individual relationships with such organisations. Fig. 7, which summarises the institutional key variables, further shows that insecure tenure and promises of outside assistance being unfulfilled, often result in passive behaviour (i.e. a general unwillingness to invest in reducing risk) on the part of slum dwellers.

Finally, it is important to point out that in the slum communities analysed, there was not only little sense of mutual rights and obligations pertaining to the settlements' maintenance and development (e.g. in terms of refraining from creating risk to others by, for example, excavating slopes below houses or constructing latrines close to declivities), but also a lack (and unequal distribution) of information on risk reduction and hence on how to achieve sustainable urban resilience. Thus, the asymmetric disaster risk that the urban poor incur is strong and rising, which also increases tension among neighbours.

Asymmetric disaster risk is the unequal distribution of the level of disaster risk experienced by people living close to and within a specific area. Hence, the asymmetric disaster risk of slum inhabitants refers to the fact that the level of disaster risk within a given slum is not constant across the entire community.

\section{UNDERSTANDING DISASTER IMPACTS}

Within the slums analysed, the key variables and causal loops identified result in the regular and presumably increasing occurrence of 'natural' disasters. As shown in Figs 3-7, disasters subsequently have a negative impact on some of the key variables, creating poverty traps. Furthermore, disasters not only have short-term impacts but also long-lasting negative effects on livelihoods and on the sustainable growth and development of settlements. Information from slum dwellers suggests that disaster impacts can be classified as immediate and delayed, as well as short- and long-lived

(a) immediate and short-lived, for example electricity failures, temporary evacuations or resettlements, blocked accesses to houses or settlements, community distress, psychological shock

(b) immediate and long-lasting, for example destruction of or damage to housing, infrastructure, household and vegetation, loss of land and personal belongings, modification of landscape, death, trauma

(c) delayed and short-lived, for example secondary hazards such as landslides during 'normal' rain or through waste water flows because of soil instability and erosion caused by disasters, burglaries because of damaged houses, reduced income

(d) delayed and long-lasting, for example illnesses caused, for instance, by waste water entering houses, accidents owing to insecure pathways, family disruptions due to a permanent move of children to other family members, contamination of environment when plastic sheets used to protect slopes from rain are blown away, reduced support from planning authorities (e.g. in terms of providing land tenure) owing to increased and unacceptable risk levels.

As with the key variables underlying risk and disaster occurrence, the immediate and delayed, short- and long-lived impacts can also be classified as being

(a) space- and infrastructure-related (which can also be called physical/technological)

(b) natural (also called environmental)

(c) socio-economic

(d) institutional.

\section{UNDERSTANDING LOCAL COPING STRATEGIES}

'We are always trying to improve, little by little, step by step, in order to become more secure.' This statement by a slum dweller living in San Salvador expresses the constant efforts that are put into coping with risk and disasters. Coping strategies have mainly been studied in rural areas, especially in relation to droughts, where disaster and development specialists have learned to appreciate their value. ${ }^{15}$ However, there seems to be comparatively little interest in coping strategies in urban areas. Key literature on disaster risk reduction commonly makes use of the term 'coping strategy', usually, however, without defining it. ${ }^{15,16}$ Based on the household-level research presented here, the following definition of coping strategy is proposed-constantly changing and adapting cognitive and behavioural efforts to manage disaster risk or disaster impacts. Importantly, these efforts influence the key variables and causal loops underlying the complex system of risk and disaster occurrence in specific slum areas.

The research revealed three types of local coping strategies used by slum dwellers living at risk

(a) risk reduction through prevention, mitigation and preparedness

(b) self-insurance-informal or formal-against possible disasters

(c) recovery from disaster impacts.

Slums are generally improved incrementally, usually by self-help and mutual help. All three coping strategies identified, which will be described further, are vital to ensure the continuing development of slums and, hence, represent an improvement in slum dwellers' standard of living and security. They include physical/technological, environmental, socioeconomic, organisational and institutional measures, and match both the types of disaster impacts and the key variables underlying risk and disaster occurrence discussed earlier.

\section{I. Risk reduction: prevention, mitigation and preparedness}

Coping strategies for risk reduction comprise prevention (or hazard reduction) to minimise or avoid hazards, mitigation to reduce vulnerabilities and preparedness to ensure effective response as soon as disasters/hazards strike. Slum dwellers use this kind of risk reduction during 'normal' times (i.e. within a pre-disaster context) in order to be less affected by future hazards/disasters. In the ideal case, risk reduction leads to an absence of disasters (as impacts will be minimal). 

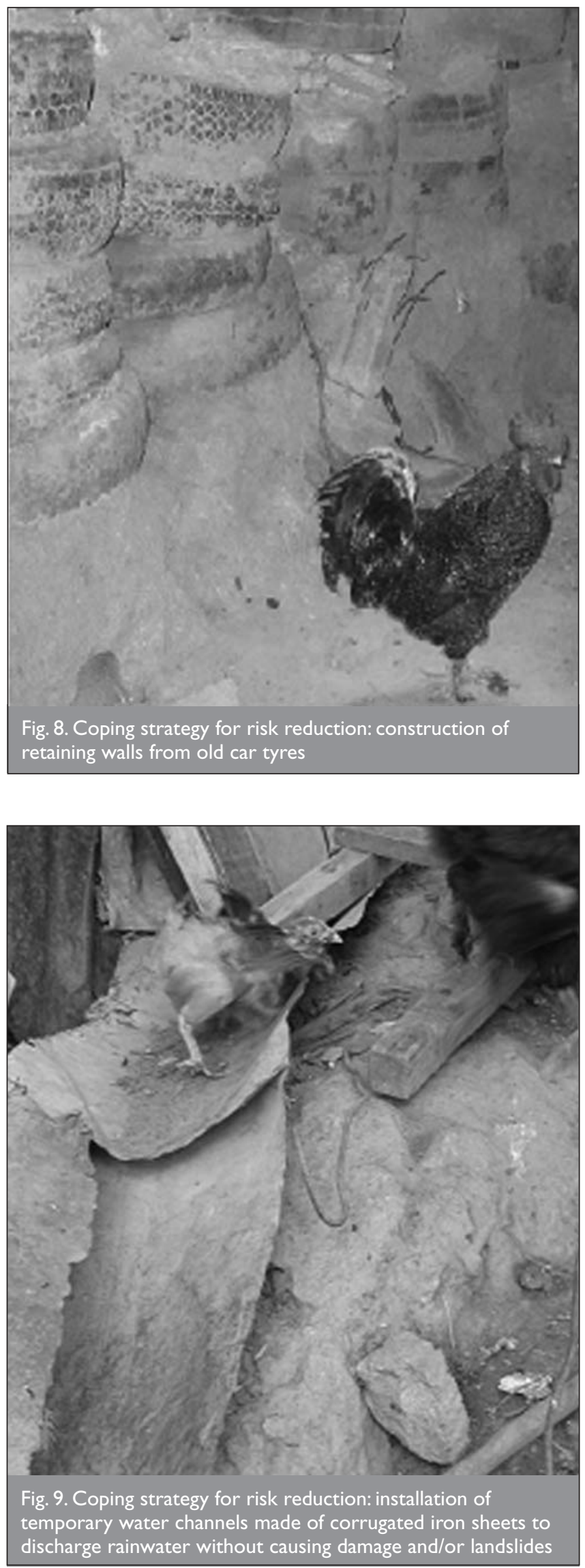

To reduce risk, El Salvadoran slum dwellers, for instance, build retaining walls or embankments with old car tyres, stones, bricks or nylon bags filled with soil and cement; plant palm trees; install temporary water gutters; remove blockages from rivers and open water channels; take jobs outside their own settlement so as to be unaffected by local disasters; temporarily move their families to higher rooms if floods are forecast; and create information structures to access information on existing risk levels and weather forecasts. Fig. 8 and Fig. 9 illustrate some risk reduction strategies. They may also adopt more emotionally oriented strategies, such as relying on their faith or simply accepting their high risk. Answers such as 'I just sit with my Bible and pray' were common. However, unbearable needs push most slum dwellers to actively adopt individualistic behaviour for survival. In fact, this study supports Twigg ${ }^{15}$ who states that expressions of belief in divine power are not incompatible with taking actions to reduce risk.

(a) Physical/technological risk reduction was identified as including structural and non-structural improvements to dwellings and their surroundings, mostly carried out on an individual basis. Structural measures include increasing the incline of roofs or prolonging roof projections for better run-off and protection of houses, or changing the location of latrines and wash places to mitigate erosion. Examples of non-structural measures are blocking waste water pipes with stones and other objects when river levels rise to avoid flooding and/or related contamination, or putting wood or bricks on roofs for added security during heavy rain or strong winds.

(b) Environmental risk reduction includes the use of natural resources (e.g. planting of trees and shrubs to prevent landslides and/or to create windbreaks) and the removal of natural resources (e.g. cutting down of bigger branches and trees located close to houses to minimise the risk of falling during bad weather) as well as the 'clean-up' of the natural environment (e.g. clearing objects blocking the flow of rivers and the cleaning of waste from slopes to mitigate flooding caused by blocked river beds or waste gutters). These measures are carried out individually and, to some extent, in cooperation with neighbours, the whole community and local or national government.

(c) Socio-economic risk reduction is predominantly individualistic and was shown to include both behavioural and cognitive measures. Economic diversification in households is, for instance, a common strategy for reducing socioeconomic vulnerabilities; this includes household members engaging in low-risk activities or activities with differing risk profiles. If one family member temporarily becomes jobless because, for instance, the local tortilleria or corn mill is destroyed by a disaster, other income sources can absorb the losses and help bridge the income shortage. Increased household income (for vulnerability reduction) is sometimes achieved through migration of family members to the USA. In 2004, more than one million Salvadorans were resident in the USA, and family remittances have become a major income source for El Salvador since the 1990s. ${ }^{17}$

(d) Organisational and institutional risk reduction is often closely related to kinship networks, mutual aid and selfhelp, or to formal and hierarchical structures for disaster risk reduction. Concrete examples include organised and coordinated community work for transporting people's belongings to higher-level streets if flooding is expected, guarding empty houses and evacuated people who are asleep on the streets during preventive evacuation, or the establishment of local committees for risk reduction. However, some strategies are also carried out individually. 


\subsection{Self-insurance}

As revealed by this research, coping strategies go beyond reducing risk through prevention, mitigation and preparedness. They also include mechanisms for self-insurance, that is the creation of formal or informal security systems during 'normal' times to help gain access to financing sources or other recovery aid in the event of a disaster. An example of self-insurance is buying and maintaining physical assets (e.g. construction materials) that can easily be sold if needed. To alleviate financial distress, one slum dweller sold seven corrugated roofing sheets and then re-roofed his home with an old car body (Fig. 10). Other examples of Salvadorans' self-insurance include having many children, putting money 'under the mattress', encouraging family members to move to the USA, joining religious institutions (which offer help after disasters) and contributing to community emergency funds.

In the slum communities visited, self-insurance appears to play a more significant role than formal insurance. Only 26 of the 331 people interviewed had access to the Salvadoran social security system. Property insurance is not available. However, while there is a general conception that slum dwellers do not have a culture of insurance, some cases showed the contrary. Through deals with entrepreneurs, some residents obtained certificates of employment that enabled them to pay into the social security system, even though they were not formally employed.

\subsection{Recovery}

Directly interlinked with self-insurance are coping strategies for disaster recovery. However, not all recovery strategies are initiated in a pre-disaster context; they can also be ad hoc.

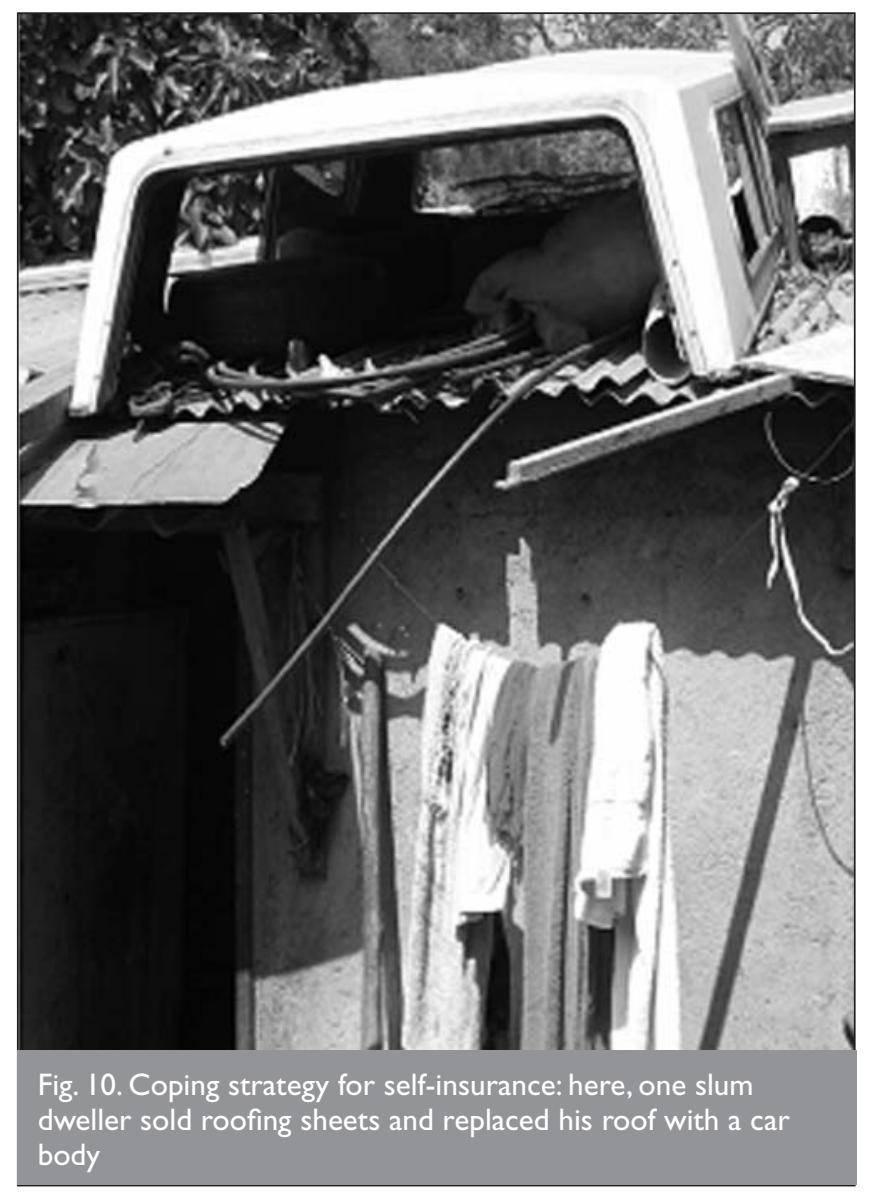

Recovery strategies were defined as 'actions taken in a postdisaster situation to recover as fast as possible from disaster impacts, that is, to regain the former status quo or become even better-off than before'.

(a) Socio-economic recovery aims at loss 'funancing', that is obtaining financial or material resources for recovery (e.g. borrowing money, using credit or savings, increasing income, reducing expenses). The strategies identified are mainly carried out individually at household level. However, lack of solidarity among members of some households occasionally erodes such efforts. In fact, complaints about family members with regard to financial help were more frequent than accolades. Nevertheless, the interviews and literature confirm that remittances from abroad play an important role in recovery. According to Agunias, ${ }^{18}$ remittances rise when an economy suffers a downturn or macro-economic shocks due to a natural disaster. Following the 2001 earthquakes, the Central Reserve Bank of El Salvador estimated that Salvadorans living abroad sent home US\$ 1.9 billion in remittances. ${ }^{19}$ As of 2004, remittances totalled US $\$ 2.5$ billion $^{17}$ and assisted more than one-fifth of all households. ${ }^{20}$

(b) Organisational and institutional recovery are for the most part related to kinship networks, mutual aid and self-help. However, they also include assistance from NGOs and governmental organisations.

\subsection{Weak coping}

In the four slums analysed, more than 100 different coping strategies were identified. (A detailed analysis of household coping strategies in El Salvador and all the different strategies identified is available in the literature. ${ }^{9}$ ) Despite this huge variety and the high importance of local coping to make slum areas more disaster-resilient, the research revealed that some of the strategies identified are weak and deficient. Slum dwellers reported that it can take them several years to recover from single events and that they are mainly dependent on outside help. Backsliding is also frequent and a barrier to achieving urban resilience.

The reasons for weak coping in urban areas in El Salvador are, first, reduced solidarity and reciprocity among households because of

(a) urbanisation and the related and increasing ease of mobility, enabling households to 'default' on their obligations to relatives and neighbours

(b) different income levels (US\$ 120-750 per household and US\$ 30-500 per worker); this fosters individualistic behaviour with better-off households opting out of mutual and hierarchical arrangements

(c) the persistent experience of bad living conditions over a period of years experienced simultaneously by most households

(d) loss of trust in both community solidarity and hierarchical structures (due, among other reasons, to corruption and factionalism).

Weak coping is, second, related to a lack of knowledge and resources due to

(a) rapidly changing contexts 
(b) slum dwellers' tendency to opt for specialised types of job so as to be able to compete economically, which makes livelihood diversification-and thus coping-difficult

(c) possession of few assets that could be sold to help themselves or others

(d) some inhabitants feeling a lack of attachment to their settlement/location because of frequent relocation; this in turn lessens their instinctive coping ability and/or leads to poorly developed coping strategies.

\section{UNDERSTANDING THE FINANCIAL IMPLICATIONS OF COPING STRATEGIES}

This research revealed that households spend an average of 9.2\% (range 0-75\%) of their income on reducing disaster risk (about $\$ 26$ out of an average monthly income of $\$ 284$ ). This is in addition to construction materials obtained for free, family members' free labour, opportunity costs of the considerable time spent on risk reduction and the negative impacts of some coping strategies (such as high interest paid to informal money lenders). Post-disaster expenses add up as well: replacement of belongings washed away during floods and landslides, recovery efforts, temporary income losses, and the gradual loss of investments put into the incremental building of housing and community infrastructure. Thus, the already scarce resources of slum dwellers erode considerably-on a constant basis, at least once every year during the winter period.

\section{MATCHING THE EFFORTS OF URBAN DEVELOPMENT ACTORS TO THOSE OF SLUM DWELLERS}

To achieve holistic disaster risk reduction and thus urban resilience, measures to tackle risk need to match local needs, capacities and dimensions of risk and-where appropriate-build on people's coping strategies. However, it was discovered that, in practice, people's efforts and their financial impacts were both generally unknown to (and hence given little consideration by) urban development actors. In this context, the following five complementary measures were identified and developed to provide a frame of reference that allows urban development actors systematically to search for and analyse potential programme measures.

(a) Hazard reduction (or prevention), which aims (to increase the capacity) to avoid or reduce the potential intensity and frequency of natural hazards that threaten households, communities and/or institutions. Programme measures can, for instance, counteract human activities that lead to the creation of new hazards or foster existing ones.

(b) Mitigation, which aims (to increase the capacity) to minimise the vulnerable condition/setting of households, communities and/or institutions to 'natural' hazards/ disasters. The inclusion of non-physical/technological vulnerability reduction is vital here.

(c) Preparedness, which aims (to increase the capacity) to establish effective response mechanisms and structures for households, communities and/or institutions so that they can react effectively during and in the immediate aftermath of potential hazards/disasters. Examples are the construction of evacuation roads to and from especially vulnerable areas, emergency shelters and protected rooms in basements (for windstorms) or top floors (for water surges) and the creation of early-warning systems that include urban risk indicators for disaster forecasting.

(d) Risk 'financing', which aims (to increase the capacity) to transfer or share risk so as to establish a 'security system' (safeguard) for households, communities and/or institutions that comes into force after potential hazard/disaster impacts and helps people obtain 'readily available' compensation.

(e) Stand-by for recovery, which aims (to increase the capacity) to establish appropriate recovery mechanisms and structures for households, communities and/or institutions that are accessible after a potential hazard/disaster. This includes mechanisms and structures for both rehabilitation and reconstruction.

Both risk 'financing' and stand-by for recovery aim to establish mechanisms and/or systems that can help slum dwellers recover quickly from hazard or disaster impacts. These measures should especially be considered for the adaptation of housing financing mechanisms. Examples are the integration of insurance mechanisms or special recovery funds. Housing microcredits, subsidies and family savings can thus become integral ex ante tools for disaster risk reduction. Moreover, the scope of social housing financing mechanisms could be extended to support the financing of risk reduction measures.

The achievement of sustainable implementation of all the five measures listed often strongly depends on the existing relations between local communities and national and municipal authorities. Therefore, improving these relationships to overcome, for instance, loss of trust in community solidarity and in hierarchical structures of planning and emergency authorities at municipal and national level can be important. Examples of related programme measures could thus be improvement of local urban governance to address community rights and obligations, as well as better pre- and post-disaster communication and decision making among the different actors in which the urban poor have a stake.

In practice, urban development actors generally consider only two (but only in part) of the five measures listed. Indeed, they often use only a few physical/technological measures of prevention and mitigation. Separation of the five measures identified during planning and implementation of development programmes can thus help urban development actors to achieve more comprehensive disaster risk reduction and, hence, urban resilience.

\section{CONCLUSIONS}

This paper has discussed, from a local perspective, key variables and causal loops underlying the complex system of disaster risk in selected slums in El Salvador and their inhabitants' related coping strategies. It presents a comprehensive 'snapshot' of what drives risk and disasters and how slum dwellers cope with the resulting precarious living situation. This new 'vision' provides fresh input into ongoing discussions that currently deal with risk and disasters only in terms of location and construction quality-aspects that are seemingly best and most simply ‘solved' through post-disaster resettlement.

The paper shows that disasters are the outcome of a non-linear development process, with key variables and disaster occurrence reinforcing each other. Disasters make the already 
precarious conditions of slum dwellers worse, creating a vicious circle of increasing risk that can result in poverty traps. The huge variety of household strategies presented and the related financial efforts to cope with risk and disasters clearly show that this interconnection is not a passive behaviour circle but is related to a combination of weak coping and inadequate outside assistance for urban development.

Although more evidence is needed, the coping strategies of urban as compared with rural slum dwellers appear not only to be weaker (i.e. less effective) but also less deliberate and more individualistic (as opposed to communitarian), with a stronger focus on housing construction and land issues and less emphasis on productive sources of livelihood. Hence the gradual slum development process, with its inherent coping mechanisms, cannot keep pace with the frequency of disaster impacts, resulting in increased insecurity. Knowing how urban development actors-through assistance in social housing and human settlement planning-could counteract such developments to assist in achieving urban resilience is thus vital.

As a first step, systems analysis and its causal loop diagrams can help urban development actors provide a better understanding of local contexts, perspectives and needs, and can assist in analysing the effectiveness of people's interrelated efforts to cope with risk and disaster impacts. Moreover, this knowledge can contribute to an improved understanding of the conditions and conditionality for the implementation of effective and sustainable project measures. This is an important step forward-urban development actors that service slum communities often do not have such information at their disposal and seldom carry out related analyses.

The research indicates that, where local coping strategies and efforts are denied, unsustainable programmes often result. Increasing risk-instead of urban resilience-is the outcome. The research outcomes, illustrated in the causal loop diagrams presented, confirm that improved housing and infrastructure in situ are generally crucial if physical/technological vulnerabilities are to be reduced. However, because of the complex system of risk and disaster occurrence, such improvements are not enough to achieve sustainable resilience of the habitats, lives and livelihoods of slum dwellers.

The analysis supports the increasingly accepted view that an integrated perspective regarding disaster risk reduction is necessary to achieve urban resilience. Hence, integrating disaster risk reduction into assistance for urban development has to combine purely physical/technological improvements with environmental, socio-economic and institutional risk reduction. In this process, the use of causal loop diagrams can help to develop and validate concrete and slum-specific project measures. This validation of potential measures is importantonly local efforts to cope with risk and disaster (which, in effect, tackle the key variables and causal loops identified in a sustainable way) should be supported by urban development actors. In fact, if possible, development efforts should

(a) encourage-and eventually scale up-strategies that increase capacities to manage risk and disaster occurrence in the short and the long term (b) offer alternative mechanisms where such strategies are non-existent.

On the basis of the analysis of the type of assistance provided by urban development actors servicing slum communities and its comparison with local efforts, five complementary measures to tackle risk were identified and developed. While people's way of coping is holistic in terms of including strategies for risk reduction, self-insurance and recovery, urban development actors look mainly at how to mitigate physical vulnerability. The five measures ascertained thus provide a frame of reference for achieving urban resilience that allows urban development actors systematically to search for and implement (more) adequate programme activities that match the needs and efforts of people living at risk. It is concluded that knowledge of, and 'keeping separate' of, the five measures during planning and implementation of urban development programmes can help ensure both sustainable poverty reduction and urban resilience.

\section{ACKNOWLEDGEMENTS}

The author is particularly grateful to Joanne Linnerooth-Bayer of the International Institute for Applied Systems Analysis (IIASA) and Alfredo Stein of the Global Urban Research Centre (GURC), University of Manchester, for commenting on draft versions of this paper. Special thanks are owed to all who agreed to be interviewed. The Swedish International Development Cooperation Agency (Sida) and the German Advisory Council on Global Change (WBGU) provided financial support for this research.

\section{REFERENCES}

1. United Nations International Strategy for Disaster Reduction. Disaster Statistics 1991-2005. UNISDR, Geneva, 2006. See www.unisdr.org/disaster-statistics/introduction.htm for further details (accessed 07/06/2006).

2. LaVell A. Prevention and mitigation of disasters in Central America: vulnerability to disasters at the local level. In Disasters, Development and Environment (VARLeY A. (ed.)). Wiley, Chichester, 1994, pp. 49-64.

3. UN-HaвiтAт. The Challenge of Slums. Earthscan, London, 2003.

4. Intergovernmental Panel On Climate Change. Climate Change 2007: The Physical Science Basis: Summary for policy makers, Fourth Assessment Report. IPCC, Geneva, 2007. See www.ipcc.ch/SPM2feb07.pdf for further details (accessed 13/11/2007).

5. Intergovernmental Panel On Climate Change. Climate Change 2007: Impacts, Adaptation and Vulnerability: Summary for Policy Makers, Fourth Assessment Report. IPCC, Geneva, 2007. See www.ipcc.ch/SPM13apr07.pdf for further details (accessed 13/11/2007).

6. See http://www.unisdr.org/eng/library/ lib-terminology-eng\%20home.htm for further details (accessed 31/10/2008).

7. See www.unmillenniumproject.org for further details (accessed 31/10/2008).

8. United Nations International Strategy for Disaster Reduction. Hyogo Framework for Action 2005-2015: Building the Resilience of Nations and Communities to Disasters. UNISDR, Geneva, 2005. See www.unisdr.org/wcdr/ intergover/official-doc/L-docs/Hyogo-framework-foraction-english.pdf for further details. (accessed 05/06/2006). 
9. WAMSLER C. Bridging the gaps: stakeholder-based strategies for risk reduction and financing for the urban poor.

Environment and Urbanization, 2007, 19, No. 1, 115-142.

10. WAMSLER C. Planning ahead-adapting settlements before disasters strike. In Hazards and the Built Environment: Attaining Built-in Resilience (BosHeR L. (ed.)). Taylor and Francis, London, 2008, pp. 317-354.

11. WAMSLER C. Managing Urban Disaster Risk: Analysis and Adaptation Frameworks for Integrated Settlement Development Programming for the Urban Poor. PhD thesis, Lund University, 2007.

12. Glaser B. G. and Strauss A. L. The Discovery of Grounded Theory-Strategies for Qualitative Research. Aldine, Chicago, 1967.

13. Haraldsson H. V. Introduction to System Thinking and Causal Loop Diagrams. Lund University, Lund, 2004, Reports in Ecology and Environmental Engineering 2004:1.

14. See www.vensim.com for further details (accessed $31 / 10 / 2008)$.

15. Twigg J. Disaster Risk Reduction: Mitigation and Preparedness in Development and Emergency
Programming-Good Practice Review 2004. Overseas Development Institute, London, 2004.

16. United Nations International Strategy For Disaster Reduction. Living with Risk: A Global Review of Disaster Reduction Initiatives. UNISDR, Geneva, 2004. See www.unisdr.org/ eng/about_isdr/bd-lwr-2004-eng.htm for further details. Accessed 05/05/2006.

17. Latin American Economic System. Migrations and remittances in Latin America and the Caribbean: intra-regional flows and macroeconomic determinants. XXXI Regular Meeting of the Latin American Council, Caracas, 21-23 November 2005.

18. Agunias D. Remittance trends in Central America. See http://www.migrationinformation.org/Feature/display. cfm?ID=393 for further details. (accessed 12/08/2007).

19. United Nations Development Programme. Reducing Disaster Risk: A Challenge for Development. UNDP, New York, 2004.

20. United Nations Development Programme. Informe Sobre Desarrollo Humano El Salvador 2005: Una Mirada al Nuevo Nosotros. El Impacto de las Migraciones. San Salvador. UNDP, San Salvador, 2005.

\section{What do you think?}

To comment on this paper, please email up to 500 words to the editor at journals@ice.org.uk.Your article will be considered for publication in the journal. The original author(s) will also be invited to respond.

Proceedings journals rely entirely on contributions sent in by urban designers, planners, civil engineers and related professionals, academics and students. Papers should be 2000-5000 words long, with adequate illustrations and references. Please visit www.thomastelford. com/journals for author guidelines and further details. 